\title{
MAGAMP REGULATED ISOLATED AC-DC CONVERTER WITH HIGH POWER FACTOR
}

\begin{abstract}
This paper evaluates the performance of magnetic amplifier regulator in isolated off-line power supplies with power factor correction stage. A research of operation modes of power converter, based on high frequency magnetic amplifiers, with power factor correction was conducted for the first time. Simplified controller circuitry is suggested and analyzed. Experimental results are reported.
\end{abstract}

Keywords: Magnetic device, power supply, power factor correction, soft switching, efficiency.

\section{Introduction}

Advances in low-loss magnetic materials continue to maintain an interest in a well founded power control technology - the magnetic amplifier (MagAmp) [1] and [2]. Numerous topologies for MagAmp regulator schemes were proposed in literature [3] - [5]. The main advantages of MagAmp are its simplicity and ruggedness. MagAmp can be controlled by relatively simple control circuitry and can provide good output regulation under wide load variations [6] and has good dynamic characteristics [7] - [10]. Studies showed that at $10 \mathrm{~kW}$ and $10 \mathrm{kHz}$ the IGBT converter losses are about $100 \mathrm{~W}$, whereas with a Magamp design the losses are as low as $25 \mathrm{~W}$. At $80 \mathrm{kHz}$ the IGBT losses are about $355 \mathrm{~W}$ while with a Magamp design they are only about $25 \mathrm{~W}$ [11]. Better efficiency also implies weight reduction of cooling system. Moreover, contrast with the abrupt switching of the semiconductor switch, MagAmp has a smooth switching trajectory dictated by the hysteresis loop. Consequently, MagAmp has soft switching properties and, hence, generates lower electro-magnetic interference. In addition, MagAmp switch requires neither snubbers [12] nor over-voltage, nor short circuit protection circuitry. On top of that, MagAmp regulator can facilitate zero voltage soft switching of the active devices of the driving power stage [13]. Recently, front end multiple output LLC resonant converter with MagAmp post regulation was demonstrated operating at $110 \mathrm{kHz}$ [14] and [15]. However, MagAmp is known to operate at even higher switching frequencies up to several hundred $\mathrm{kHz}$ [16] and [17]. Therefore, application of high-frequency MagAmps is a viable solution for implementing converters with multiple isolated high-current regulated outputs.

Recent regulations regarding the line current quality have made Power Factor Correctors (PFC) a standard utility interface stage for most electronic equipment that uses ac-line power. However, the high output voltage of the PFC corrected rectifiers requires down-stream dc-dc converter having larger step down ratio. This also increases the voltage stress on the semiconductor switches. Clearly, operation at higher voltage has an effect on the overall efficiency of the off line ac-dc converter.

This paper describes an isolated, MagAmp regulated ac-dc converter with good dynamic characteristics and high power factor within a wide range of the load current. A simple MagAmp control circuit is proposed. The objective of this paper is to reevaluate the performance of MagAmp regulated power stage in off-line (grid connected) applications. Experimental results are reported.

\section{General concept}

In order to achieve low-harmonic line current, isolation capability and dc output regulation a three stage approach is considered as shown in Fig. 1 [18]. One Cycle Controlled (OCC) Power Factor Pre-regulator is applied to attain high power factor utility interface, transformer isolated self oscillating half-bridge power oscillator implements an isolated high frequency link, whereas MagAmp post-regulator is employed to provide output voltage regulation.

\footnotetext{
* ${ }^{1}$ Volodymyr Yaskiv, ${ }^{2}$ Alexander Abramovitz, ${ }^{3}$ Keyue Smedley, ${ }^{1}$ Anna Yaskiv

${ }^{1}$ Department of Testing Instruments and Radio Computer Systems, Ternopil Ivan Puluj National Technical University, Ternopil, Ukraine

${ }^{2}$ Department of Electrical and Electronics Engineering, Sami Shamoon College of Engineering, Beer-Sheva, Israel

${ }^{3}$ Department of Electrical Engineering and Computer Science, University of California, Irvine, USA

E- mail: yaskiv@yahoo.com
} 


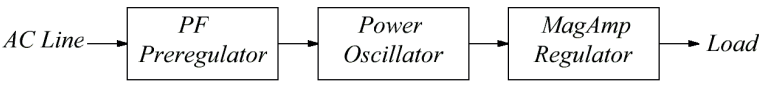

Fig. 1 Block diagram of the proposed ac-dc converter

The purpose of the PF pre-regulator is twofold [18]. First, is to provide a near sinusoidal line current and reduce line harmonics and secondly, to provide the pre-stabilized dc voltage for the Power Oscillator. The PF pre-regulator output voltage is supported by large reservoir capacitance, designed to provide a sufficient holding time in case of utility sag. The Power Oscillator stage is fed by the output voltage of the PF preregulator and drives the step-down isolating transformer with a high voltage, high frequency square wave excitation signal. High frequency operation allows miniaturization of the power transformer size, weight and cost. Due to the self-oscillating nature of the circuit neither bootstrap drivers nor auxiliary power supply are needed. The MagAmp post-regulator is implemented at the power transformer secondary and provides regulation of the output voltage. Since the MagAmp control circuits are implemented entirely on the secondary side, there is no need for isolated feedback path, which further simplifies the circuitry [18].

\subsection{The PF pre-regulator stage}

The proposed high power factor pre-regulator uses a boost power stage and OCC method to regulate the output voltage and shape the line current [18] and [19]. The diagram of the PF Preregulator with a boost power stage and OCC controller is shown in Fig. 2. Here, the downstream power stages are represented by the equivalent load resistor $R_{L}$. Theoretically, under the OCC control the boost converter exhibits resistive input characteristic As a result, the line current is in phase with the input voltage and harmonic free. Therefore, the power factor of the OCC controlled rectifier equals unity. By keeping the PF pre-regulator output voltage $V_{o}$ at a constant level, the voltage feedback loop establishes the power balance so that the average ac power drawn from the line equals the dc power demands of the load. To attain this control objective, the error amplifier signal $V_{m}$ is modulated to adjust the average power flow. The advantages of the OCC control method are the simple and low cost PF Pre-regulator circuitry as well as good and reliable performance [18]. Detailed description of the controller and design procedure of OCC high $\mathrm{PF}$ rectifier can be found in [20].

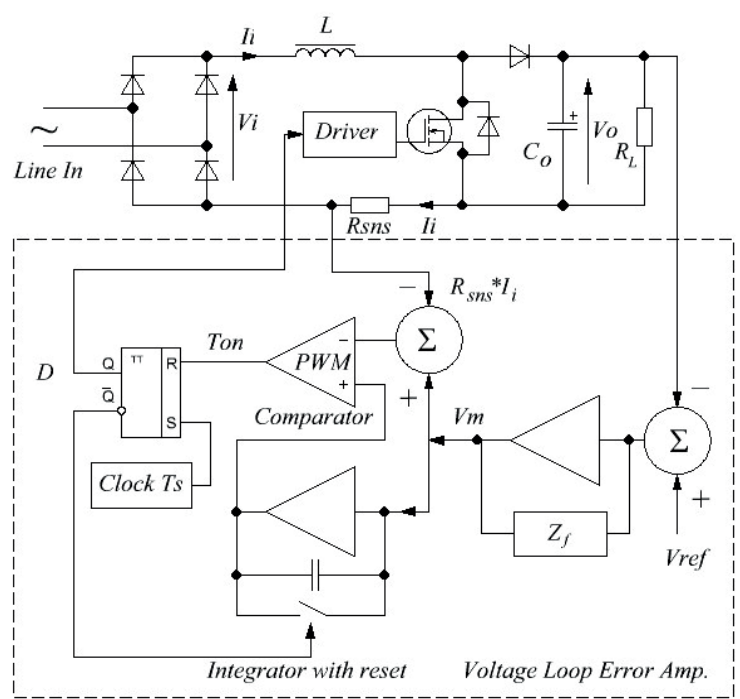

Fig. 2 Block diagram of the OCC controlled PF pre-regulator Boost rectifier

\subsection{The power oscillator stage}

The Power Oscillator, shown in Fig. 3, is a modified selfoscillating half-bridge circuit derived from [4]. The circuit is comprised of power transistors Q1 and Q2, free-wheeling diodes D9 and D10, splitting capacitors C5 and C6, which are also used as the hold-up capacitors, and the power transformer T2. The drive signal is obtained by the feedback transformer T3 placed in parallel to the oscillator output. The drive transformer $\mathrm{T} 1$ has two split anti-phase drive windings $\mathrm{N} 1$ for each power transistor and a proportional base drive winding $\mathrm{N} 2$. The advantage of the half-bridge stage is that it applies only half of the supply voltage to the transformer primary and so provides additional voltage step down. This allows lowering the transformer turn ratio as well as transformer's primary magnetizing inductance.

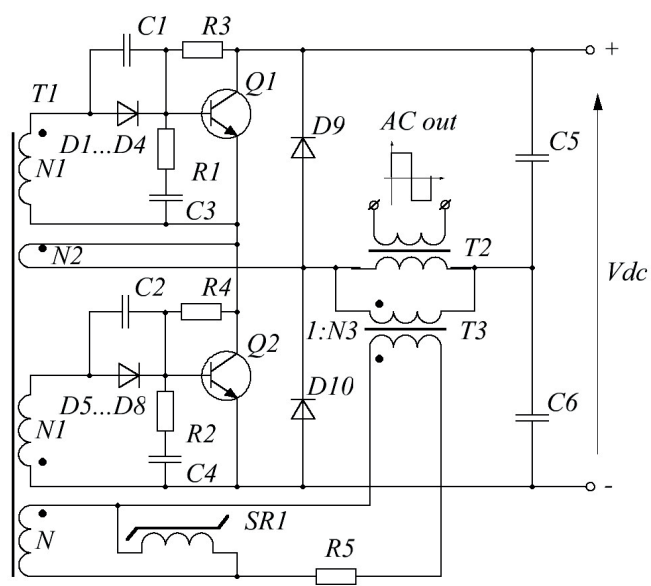

Fig. 3 Schematic diagram of the Power Oscillator 
The oscillator cycle is determined by the time required for the saturable reactor, SR1, to slew from positive to negative saturation and then back again to positive saturation and is a function of SR1 parameters, that is, number of turns, effective core cross section area and maximum flux density of the saturable reactor $\mathrm{SR} 1, \mathrm{~N}_{\mathrm{SR}}, \mathrm{A}, \mathrm{B}_{\max }$, and applied voltage. The voltage across SR1 equals the voltage across five conducting diodes $5 \mathrm{~V}_{\text {on }}$ reflected towards the saturable reactor via the drive transformer with turns ratio of $\frac{N}{N_{1}}$. Therefore, the approximate expression for the oscillator frequency can be derived as:

$$
f_{s}=\frac{5 N V_{o n}}{4 N_{1} N_{S R} A B_{\max }}
$$

The advantage of the proposed scheme is that the saturable reactor SR1 keeps the positive and negative half-cycles of the oscillator's output voltage waveform in perfect balance. This prevents saturating the power transformer. Thus, no dc blocking capacitor is needed at the transformer's primary.

\subsection{A quick review of MagAmp post-regulator and control circuit}

The MagAmp post-regulator is implemented as a push-pull full-wave circuit [5] at the secondary of the power transformer, $\mathrm{T}$, as shown in Fig. 4. The post-regulator is comprised of a pair of the MagAmp switches SR1 and SR2; power rectifier diodes D1-D2; a free-wheeling diode DFW and a second order LC output filter.

As compared to a single ended MagAmp circuit, the push-pull MagAmp configuration has the advantages of the symmetrical operation and doubled dc output voltage.

Here, both MagAmp switches operate with current reset. The reset current $I_{R}$ is provided by the controller as discussed below. The steering diodes DR1 and DR2 naturally steer the reset current $I_{R}$ towards the device to be reset. Each MagAmp is wound using two parallel strands of litz wire on the same core. The parallel connection of the MagAmp windings lowers the equivalent resistance of the conduction path and accordingly, lowers the power losses of the power stage under high load current.

There are different approaches to control circuit design [21]. The proposed MagAmp control circuit is shown in Fig. 5. This circuit is a simplification of that used in [9]. The circuit is fed directly by the output voltage, Vout. Resistor divider R1, R2 determines the feedback ratio, breakdown diode D8 provides the voltage reference, whereas the PNP transistor Q3 realizes a transconduction error amplifier, Gm. The compensation network is constituted of $R_{e 1}, R_{e 2}, C_{e}$. The collector current of Q3 is applied to MagAmp switches as the reset current $I_{R}$.

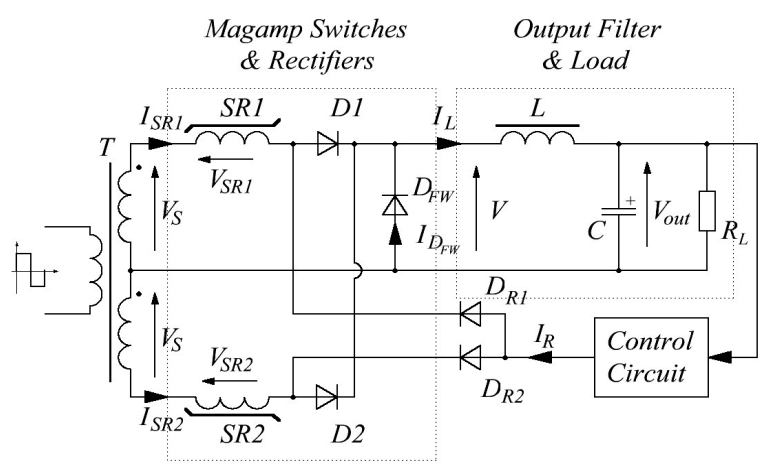

Fig. 4 Push-pull MagAmp regulator circuit

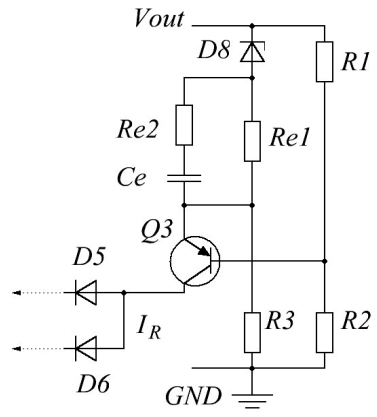

Fig. 5 MagAmp control circuit

Under closed loop action, assuming also that the voltage drop across $\operatorname{Re} 1$ is negligible, the converter's steady state output voltage is established according to:

$V_{\text {out }}=\left(V_{z}+V_{E B o n}\right) \cdot\left(1+\frac{R_{2}}{R_{1}}\right)$,

$V z$ is the breakdown voltage of $\mathrm{D} 8$ and $V_{E B o n}$ is the ON voltage of Q3 emitter - base junction.

\subsection{Derivation of approximate MagAmp large signal relationships}

In the blocking state the MagAmp has to sustain the pulse voltage $V_{p}$ with only a negligible current $i$ flowing through the device. Thus, according to the Faraday's law:

$V_{p}=\frac{d \lambda}{d t}=\left(\frac{d \lambda}{d i}\right) \frac{d i}{d t}$

where $\lambda$ is the flux linkage.

Due to the hysteresis of the core material, $\left(\frac{d \lambda}{d i}\right)$ is a non linear function. However, modern materials recommended for implementation of MagAmps have a relatively sharp hysteresis loop. The sharpness property allows defining the average 
permeability $\mu=\mu_{0} \mu_{r}$ of the MagAmp core along the steep segment of the B-H curve. This linearization of the B-H curve is useful to obtain simple approximate results to facilitate easy design of the converter. Relying on the assumption above, a simple approximate model of the MagAmp regulator is derived introducing the average inductance of the MagAmp defined as:

$$
L_{S R}=\frac{\overline{d \lambda}}{d i}=N_{m a}^{2} \frac{\mu A_{e}}{l_{e}}
$$

where $A_{e}$ is the MagAmp core effective cross area; $l_{e}$ is the MagAmp core effective length; $N_{m a}$ is the number of turns of the MagAmp.

Rearranging (3) and applying (4), the MagAmp blocking time, $\Delta t$ can be expressed as:

$\Delta t=L_{S R} \frac{\Delta I}{V_{p}}=L_{S R} \frac{I_{\max }+I_{R}}{V_{p}}$

where:

$\Delta I=I_{\max }-\left(-I_{R}\right)$

is the current swing from the reset operating point $R$ established by the (negative) reset current $\left(-I_{R}\right)$ to the maximum (positive) current $I_{\max }$ on the verge of MagAmp saturation, approximated by:

$$
I_{\max }=\frac{H_{\max } l_{e}}{N_{m a}}=\frac{B_{\max } l_{e}}{\mu N_{m a}}
$$

Here, $B_{\max }$ is the maximum flux density of the MagAmp core material.

As shown in Fig. 5, MagAmp switches operate in a complementary fashion either in the positive or negative half cycle. Once saturated at instance $\Delta t$, the MagAmp remains in saturation till the rest of the half-cycle $\frac{1}{2} T_{s}$. Thus, the MagAmp allows the voltage to appear at the input terminals of the output filter for the duration of:

$T_{\text {on }}=\frac{1}{2} T_{s}-\Delta t=\frac{1}{2} T_{s}-\frac{L_{S R}}{V_{p}} I_{\max }-\frac{L_{S R}}{V_{p}} I_{R}$

Hence, the average voltage applied to the input terminals of the output filter by the push-pull MagAmp stage is:

$$
\begin{aligned}
& V_{a v}=\frac{2}{T_{s}}\left(V_{p} T_{o n}\right)=V_{p}-2 f_{s} L_{S R} I_{\max }-2 f_{s} L_{S R} I_{R}= \\
& =V_{a v \max }-2 f_{s} L_{S R} I_{R}
\end{aligned}
$$

where $f_{s}=\frac{1}{T_{s}}$ is the switching frequency, and $V_{a v \max }$ is the maximum average voltage that could be attained with zero reset current:

$$
V_{a v \max }=V_{p}-f_{s} L_{S R} I_{\max }=V_{p}-2 f_{s} N_{\text {ma }} A_{e} B_{\max }
$$

Equations (9), (10) constitute a simple approximate average large signal behavioral model of the MagAmp switch. More accurate model of MagAmp was derived in [10] and [11], however, the relative complexity of those makes it inconvenient to be used by a circuit designer.

\subsection{Control loop small signal relationships}

The MagAmp controller is implemented entirely on the secondary side of the power transformer and employs a single voltage loop. Average model of MagAmp control loop after [9] is shown in Fig. 6. Here, $H_{m a}(s)$ is the average MagAmp small signal transfer function, $H_{d}(S)$ is the MagAmp delay transfer function and $H_{f}(S)$ is the output filter transfer function. The voltage reference $V_{\text {ref }}$, the feedback $\beta$, the summer and the error amplifier transfer function $G_{m}(S)$, are implemented by the controller circuitry. The resulting MagAmp post-regulator loop-gain, see Fig. 8 , is obtained as:

$G_{L}(S)=\beta G_{m}(S) H_{m a}(S) H_{d}(S) H_{f}(S)=$

$=\left(\frac{R_{1}}{R_{1}+R_{2}}\right)\left(-\frac{1}{R_{E}}\right)\left(\frac{1+\frac{S}{\omega_{z}}}{1+\frac{S}{\omega_{p}}}\right)\left(-2 f_{s} L_{S R}\right)\left(\frac{1-\frac{S}{4 f_{s}}}{1+\frac{S}{4 f_{s}}}\right) \times$

$\times \frac{1}{1+\frac{1}{Q}\left(\frac{S}{\omega_{n}}\right)+\left(\frac{S}{\omega_{n}}\right)^{2}}$

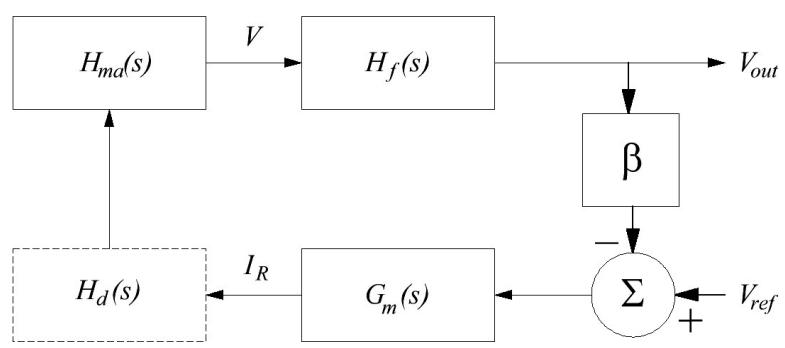

Fig. 6 Average model of MagAmp control loop

\section{Experimental results}

The experimental converter circuit was built and tested. The converter was designed to operate from the universal line 90-240 Vac and provide $24 \mathrm{Vdc}$ output at $10 \mathrm{~A}$ load current. The switching frequency of the power factor pre-regulator was $85 \mathrm{kHz}$ whereas the isolation stage half-bridge was operated at $50 \mathrm{kHz}$. The converter exhibited stable and reliable operation within the entire load and line range. The experimental characteristics of the proposed converter were obtained for $230 \mathrm{Vac}, 115 \mathrm{Vac}, 90 \mathrm{Vac}$ line, whereas the load power was varied in the $10 \%-100 \%$ range.

\subsection{Experimental steady state characteristics}


Steady state characteristics of the experimental converter are presented in Figs. 7 and 8.

Fig. 7 Power Factor as function of line voltage and output power
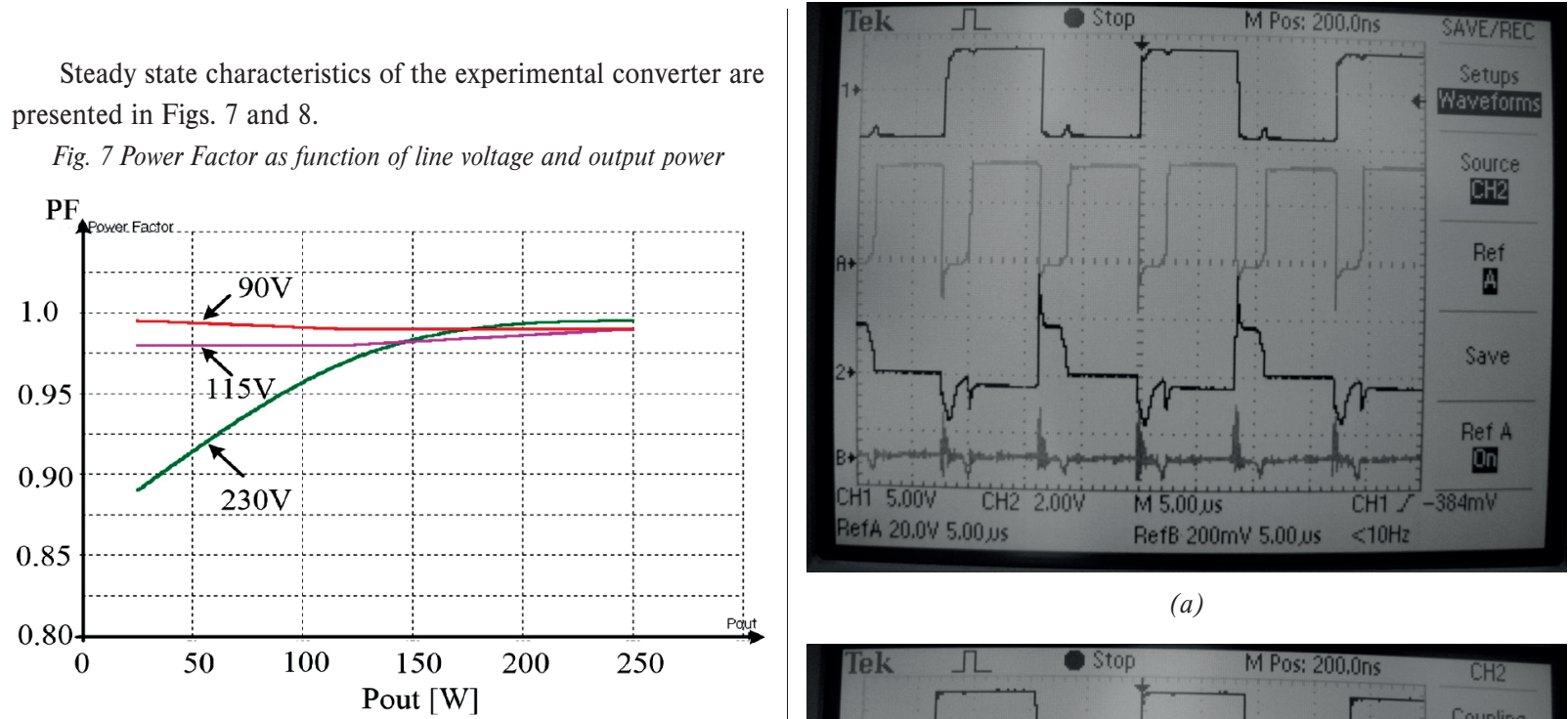

(a)
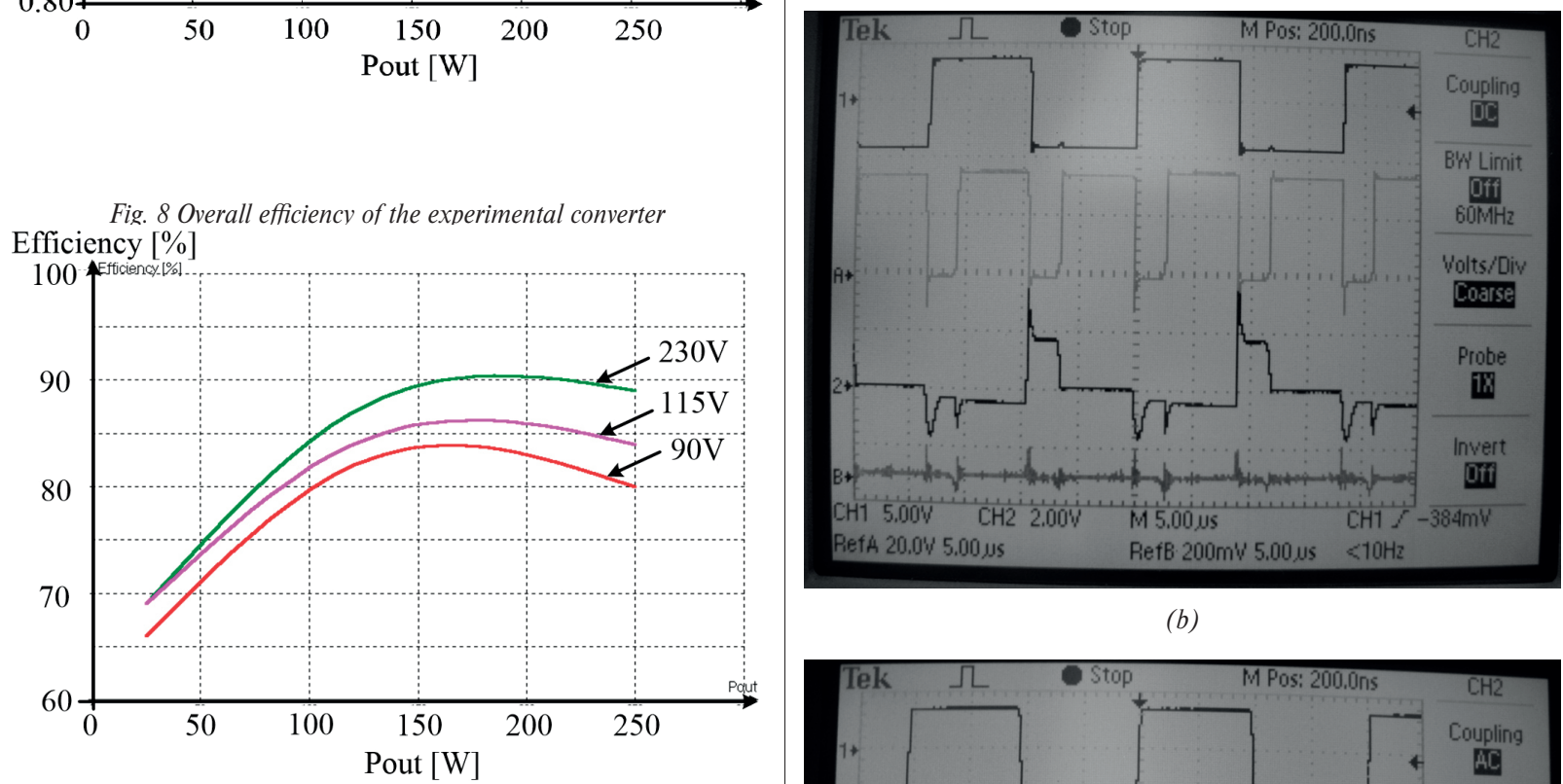

as function of output power and line voltage.

\subsection{Experimental waveforms}

Experimental waveforms of MagAmp regulator and line voltage and current are presented in Figs. 9 and 10 respectively.

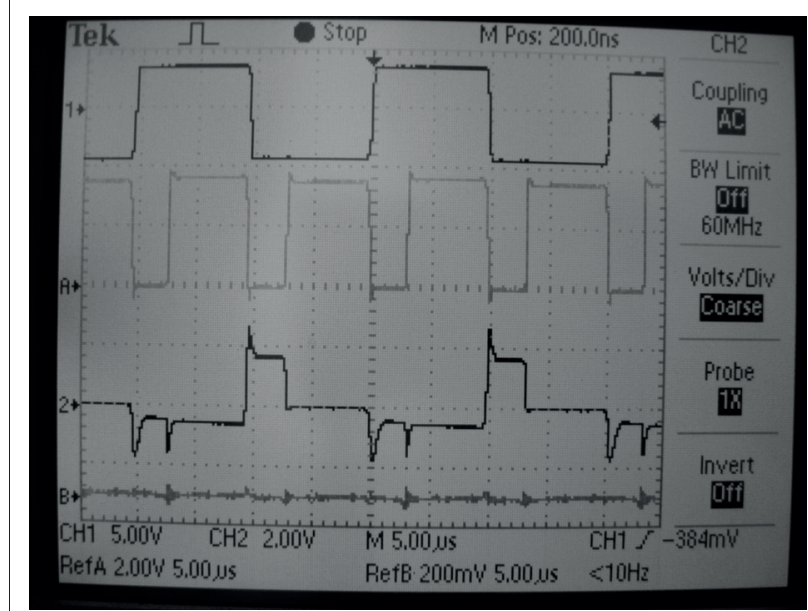

(c)

Fig. 9 Experimental waveforms of MagAmp regulator under different loading conditions: Pout $=240 \mathrm{~W}(\mathrm{a})$; Pout $=120 \mathrm{~W}(\mathrm{~b})$; Pout $=25 \mathrm{~W}$ (c). Ch1: Power transformer secondary voltage (50 V/Div); Ch2: Magamp voltage (50 V/Div); Ref. A: Input voltage of output filter (20 V/Div); Ref. B: Output voltage ripples (200 mV/Div). Horizontal scale 5 uSec. 


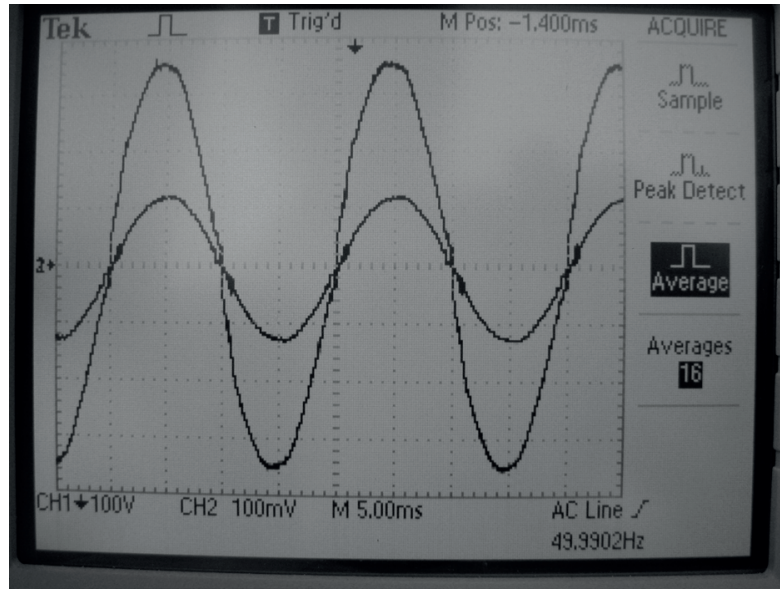

(a)

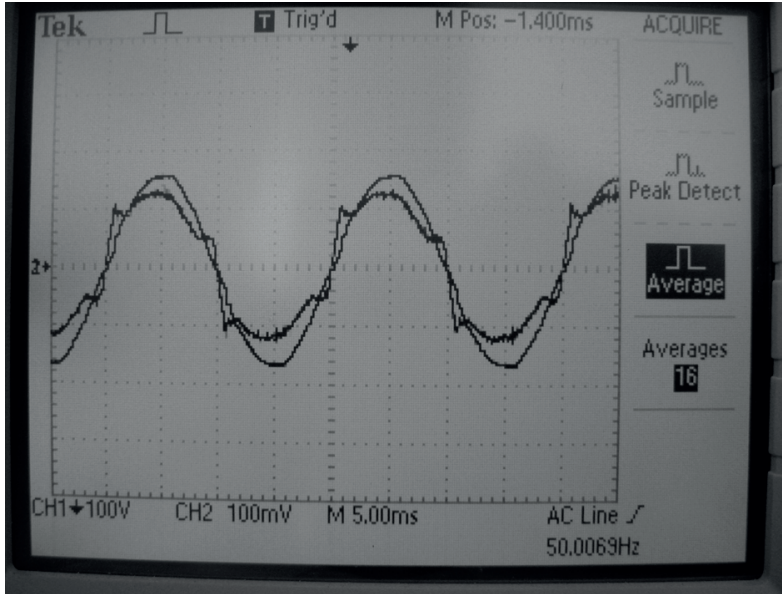

(b)

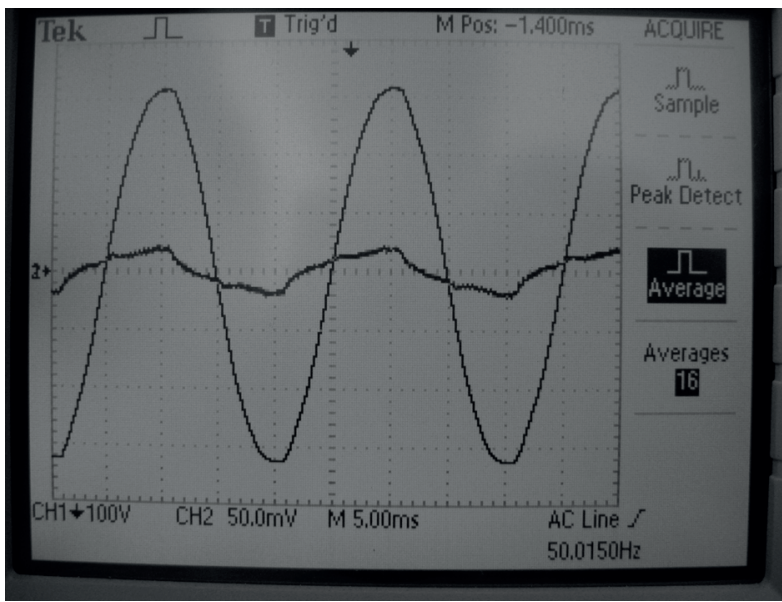

(c)

Fig. 10 Experimental waveforms of line voltage and current: (a) Pout $=240 \mathrm{~W}, \mathrm{~V}=90 \mathrm{Vrms}$, Ch2: Line current (1.33 Amp/Div); (b) Pout $=120 \mathrm{~W}, V_{\text {line }}=115 \mathrm{Vrms}$, Ch2: Line current $(1.33 \mathrm{Amp} / \mathrm{Div})$; (c) Pout $=25 \mathrm{~W}, V_{\text {line }}=90 \mathrm{Vrms}$, Ch2: Line current $(0.67 \mathrm{Amp} / \mathrm{Div})$. Ch1: Line voltage (100 V/Div); Horizontal scale $5 \mathrm{mSec}$.

\section{Conclusion}

This paper reevaluated the performance of MagAmp regulated, isolated, ac-dc converter with high power factor preregulator. A simple MagAmp control circuit was proposed.

The experimental converter was designed to provide $24 \mathrm{Vdc}$ at $10 \mathrm{~A}$ output and provided adequate characteristics within a wide range of the load current. Under full load a $0.1 \mathrm{~V}$ output ripple in the steady state was observed. The overall efficiency of the converter reached peak value of $91 \%$ at medium power level. The experimental data suggests that the PF pre-regulator stage conduction losses have a severe impact on the converter efficiency, which deteriorates as the line voltage is lowered.
Particularly under light load conditions the efficiency drops to the minimum of $65 \%$ as the controller power and switching losses become comparable to the load power.

As can be seen from the experimental waveforms, MagAmp created favorable switching conditions to the power oscillator transistors so that no overshoot or ringing was observed in the power oscillator waveform. The regulator circuits are implemented entirely on the low voltage secondary side so that no isolated feedback circuits are required. Simplicity, ruggedness and reliability as well as soft switching make MagAmp a viable solution for implementing converters with multiple isolated highcurrent regulated outputs. 


\section{References}

[1] Mag Amp Cores and Materials, Technical Bulletin, BULLETIN SR-4, Magnetics Inc., available on line at: http://www.mag-inc.com/ design/technical-documents.

[2] MAMANO, B.: Magnetic Amplifier Control, for Simple, Low-cost, Secondary Regulation, Unitrode corp. slup129.

[3] JAMERSON, C., CHEN, D. Y.: Magamp Post Regulators for Symmetrical Topologies with Emphasis on Half-bridge Configuration, IEEE Transactions on Power Electronics, 1993, 8(1), pp. 26-29.

[4] WEN, C. C., CHEN, C. L., CHEN, W., JIANG, J.: Magamp Post Regulation for Flyback Converter, Proc. of IEEE Power Electron. Spec. Conf., 2001, pp. 333-338.

[5] CHEN, W., HAN, J., WEN, C. C.: Bi-directional Resetting Scheme of the Magamp Post-regulator, Proc. of IEEE Appl. Power Electron. Conf., 2002, pp. 838-842.

[6] LEE, J., CHEN, D. Y., JAMERSON, C.: Magamp Post Regulators-practical Design Considerations to Allow Operation under Extreme Loading Conditions, Proc. of IEEE APEC, 1988, pp. 368-376.

[7] LEE, J., CHEN, D. Y., WU, Y. P., JAMERSON, C.: Modeling of Control Loop behavior of Magamp Post Regulators, IEEE Trans. Power Electron., vol. 5, pp. 476-483, Oct. 1990.

[8] YANG, C. H., CHEN, D. Y., JAMERSON, C., WU, Y. P.: Stabilizing Magamp Control Loop by Using an Inner-loop Compensation, IEEE Trans. Power Electron., vol. 6, pp. 419-429, July 1991.

[9] JOVANOVIC, M. M., HUBER, L.: Small-signal Modeling of Magamp PWM Switch”, IEEE Trans. on Power Electr., vol. 14, No. 5, Sep. 1999, pp. 882-889.

[10] CHEN, Y.-T., CHEN, D. Y.: Small-Signal Modeling of Magnetic Amplifier Post Regulators with Current-Mode Control, IEEE Trans on Ind. Electr., vol. 47, No. 4, Aug. 2000, pp. 821-831.

[11] AUSTRIN, L., FIGUEROA-KARLSTROM, E., ENGDAHL, G.: Evaluation of Switching Losses in Magnetic Amplifiers as an Alternative to IGBT Switching Technologies, $4^{\text {th }}$ IET Intern. Conference on Power Electronics, Machines and Drives (PEMD 2008) York, April 2008, pp. 250-254.

[12] DUDRIK, J., BODOR, M., TRIP, N. D.: Operation Analysis of Soft Switching PWM DC-DC Converter with Secondary Snubber, Communications - Scientific Letters of the University of Zilina, No. 3, 2013.

[13] WATSON, R., LEE, F. C.: Analysis, Design, and Experimental Results of a 1kW ZVS FB PWM Converter Employing Magamp Secondary-side Control, IEEE Transactions on Industrial Electronics, 1998, 45(5), pp 806-814.

[14] HANG, L. J., GU, Y. L., LU, Z. Y., QIAN, Z. M., XU, D. H.: Magamp Post Regulation for LLC Series Resonant Converter with Multi-output, Proc. of IEEE IECON, Nov. 2005, pp. 628-632.

[15] HANG, L., WANG, S., GU, Y., YAO, W., LU, Z.: High Cross Regulation Multi-output LLC Series Resonant Converter with Magamp Post-regulator, IEEE Trans. Ind. Electr. vol. 58, No. 9, pp. 3905-3913, 2011.

[16] FISHER, R., NGO, K., KUO, M.: A 500 kHz, 250 W DC-DC Converter with Multiple Outputs Controlled by Phase-Shifted PWM and Magnetic Amplifiers, Proc. of High Frequency Power Conversion Conference, pp. 100-110, May 1988.

[17] HIRAMATSU R., MULLET, C. E.: Using Saturable Reactor Control in $500 \mathrm{kHz}$ Converter Design, Proc. of the Tenth National Solid-State Power Conversion Conference, Powercon 10 record, pp. F-2.1-F-2.10.

[18] YASKIV, V.; ABRAMOVITZ, A.; SMEDLEY, K.: MagAmp Power Converters with Low Level EMI, Proc. of Experience on Designing and Application of CAD Systems in Microelectronics (CADSM), $201312^{\text {th }}$ Intern. Conference on the 19-23 February, 2013, pp. 388-395.

[19] LAI, Z., SMEDLEY, K.: A Family of Continuous-Conduction-Mode Power-Factor-Correction Controllers Based on the General Pulse-Width Modulator, IEEE Trans. on Power Electronics, vol. 13, pp. 501-510, 1998.

[20] BROWN, R., SOLDANO, M.: One Cycle Control IC Simplifies PFC Designs, Proc. of APEC '05 Conf., Austin, TX, 6-10 March, 2005 vol. 2, pp. 825-829.

[21] DRGONA, P., PRIKOPOVA, A., FRIVALDSKY, M., PRIECINSKY, M.: Simulation Based Method for Design and Application of Digital Control System, Communications - Scientific Letters of the University of Zilina, vol. 2A, 2011. 